\title{
A.R. Jha: Next-generation batteries and fuel cells for commercial, military, and space applications, supercapacitors-materials, systems, and applications
}

\author{
CRC Press, Boca Raton 2012, 67.02 €; ISBN: 978-1-4398-5067-1, XXIX +368 p.
}

\author{
Rudolf Holze
}

Received: 13 November 2014 / Accepted: 13 November 2014/Published online: 25 November 2014

(C) Springer-Verlag Berlin Heidelberg 2014

Systems for energy storage are needed everywhere ranging from tiny ones in sensors (and even smaller applications) to really large ones needed in connection with wind parks and photovoltaic arrays. Because electric energy cannot be stored on a large scale directly, devices employing energy conversion and storage are in high and daily growing demand. Among promising candidates, electrochemical systems occupy a particularly promising position. The rapid progress across this field of research and development appears attractive at first glance for potential authors; at second glance, books are perhaps not the most suitable means of communication because they will become outdated soon. Installation of new bachelor and master courses at many universities and a growing interest in the fundamentals as well as an overview of the state of art justify textbooks and monographs - provided that they are written with a clearly defined aim and purpose keeping an eye on the assumed and expected reader. And this way, they should cover either the complete field in a comprehensible and coherent way or they should focus on parts of it in a reasonable and intelligible approach.

The present book written by a prolific author who has previously covered a rather wide field of topics looks at first glance like a welcome addition promising a view into the future. The reader will discover soon that any expectations will be disappointed fast and thoroughly. Already the extremely detailed table of contents provides dubious promises: a rather mixed and unsystematic collection of subjects frequently organized into three sections - with headers - onto a single page in the latter text. Topics range erratically from fuel cells to low-power batteries for medical applications, rechargeable ones for military uses and for electric and hybrid vehicles. Sometimes, the reader cannot escape the feeling that whatever turned up on the desk of the author made it into the book without wasting a second on the question, where it might fit best. Certainly, nuggets of information can be found: A figure showing the energy density as a function of operating temperature or the self-discharge for many different systems are hard to find elsewhere (many authors apparently do not even waste a thought on these topics of high practical importance), in particular for so many systems in a single picture. But these few highlights can hardly compensate the vast number of flaws and errors. Frequently, the author manages to contradict himself within a single sentence. The book is definitely neither a textbook helpful for a student at any level nor a handbook for the researcher. It is - at best - a nice but minor addition for an already well-equipped library dealing with the topic addressed above, and not more.

R. Holze, Chemnitz

R. Holze $(\bowtie)$

Institut für Chemie, Technische Universität Chemnitz, Chemnitz, Germany

e-mail: Rudolf.holze@chemie.tu-chemnitz.de 